\title{
Cost-Utility Analysis of Arthroscopic Rotator Cuff Repair: A Prospective Health Economic Study Using Real-World Data
}

\author{
Cécile Grobet, M.Sc., Laurent Audigé, Ph.D., Klaus Eichler, M.D., Flurina Meier, M.Sc., \\ Beatrice Brunner, Ph.D., Simon Wieser, Ph.D., and Matthias Flury, M.D.
}

\begin{abstract}
Purpose: To assess the change in quality of life (QOL) and costs for patients with rotator cuff tears after arthroscopic rotator cuff repair (aRCR) compared with continued nonoperative management, using real-world evidence. Methods: Patients indicated for aRCR were included in a prospective study and followed up to 2 years after surgery (postop) for all measurements. QOL (EQ-5D-5L) and shoulder function (Constant Score, Oxford Shoulder Score, subjective shoulder value) were assessed. Sixteen major insurance companies provided all-diagnoses direct medical costs in Swiss francs (CHF; 1 CHF $=1.03$ USD). Baseline data at recruitment and costs sustained over 1 year before surgery (preop) served as a proxy for nonoperative management. Total direct medical costs to gain 1 extra quality-adjusted life year (QALY) were calculated as the incremental costeffectiveness ratio (ICER; mean of 2 years postop compared with 1 year preop) from a societal perspective. Subgroup analyses were separately performed for traumatic (trauma-OP) and degenerative (degen-OP) rotator cuff tear patients. Sensitivity analyses for aRCR patients included more intensive nonoperative treatment with corresponding QOL gain. The relationship between QOL and shoulder function was explored using regression analysis. Results: For 153 aRCR patients (mean age 57 years; $63 \%$ male), the mean EQ-5D index improved from 0.71 (preop) to 0.94 (1 year postop) and 0.96 (2 years postop). Mean total costs increased from 5,499 CHF (preop) to 17,116 CHF ( 1 year postop), then decreased to 4,226 CHF (2 years postop). The ICER for all aRCR patients was 24,924 CHF/QALY (95\% confidence interval [CI] 16,742 to 33,106) and 17,357 CHF/QALY (95\% CI 10,951 to 23,763$)$ and $36,474 \mathrm{CHF} / \mathrm{QALY}(95 \% \mathrm{CI} 16,301$ to 56,648$)$ for the trauma-OP and degen-OP groups, respectively. QOL and shoulder function were significantly associated $(P<.001)$. Conclusions: For RC patients treated at a specialized Swiss orthopaedic clinic, aRCR is a cost-effective intervention associated with clinically relevant improvement in QOL up to 2 years after repair compared with prior nonoperative management. Level of Evidence: Economic Analyses - Developing an Economic Model, Level II
\end{abstract}

$\mathbf{R}$ otator cuff (RC) tears are frequently painful and associated with limitations in shoulder motion and strength that can result in impairment affecting everyday activities and working ability. They are caused

From Research and Development, Schulthess Klinik, Zurich, Switzerland (C.G., L.A.); Shoulder and Elbow Surgery, Schulthess Klinik, Zurich, Switzerland (C.G., L.A., M.F.); the Winterthur Institute of Health Economics, Zurich University of Applied Sciences, Winterthur, Switzerland (K.E., F.M., B.B., S.W.); and the Center for Orthopedics $\theta$ Neurosurgery, In Motion, Wallisellen, Switzerland (M.F.).

Cécile Grobet and Laurent Audigé are co-first authors.

The authors report the following potential conflicts of interest or sources of funding: B.B. reports grants from Mäxi Foundation, Bank Vontobel Charitable Foundation, Winterthur Network of Health Economics. C.G. reports grants from Mäxi Foundation, Bank Vontobel Charitable Foundation, Winterthur Network of Health Economics. F.M. reports grants from Mäxi Foundation, Bank Vontobel Charitable Foundation, Winterthur Network of Health Economics. K.E. reports grants from Mäxi Foundation, Bank Vontobel Charitable Foundation, Winterthur Network of Health Economics. L.A. reports grants from Mäxi Foundation, Bank Vontobel Charitable Foundation, either by direct trauma or age-related degenerative changes. RC tears increasingly affect the working population, with a current average insurance payment of 26,412 Swiss Francs (CHF) per trauma case in

Winterthur Network of Health Economics. M.F. reports grants from Mäxi Foundation, Bank Vontobel Charitable Foundation, Winterthur Network of Health Economics; personal fees from Arthrex GmbH S.W. reports grants from Mäxi Foundation, Winterthur Network of Health Economics. Full ICMJE author disclosure forms are available for this article online, as supplementary material.

Received August 12, 2019; accepted February 4, 2020.

Address correspondence to Laurent Audigé, Ph.D., Schulthess Klinik, Department of Teaching, Research and Development, Lengghalde 2, CH-8008 Zurich,Switzerland.E-mail: laurent.audige@gmail.com

(C) 2020 THE AUTHORS. Published by Elsevier Inc. on behalf of the Arthroscopy Association of North America. This is an open access article under the CC BY-NC-ND license (http://creativecommons.org/licenses/by-nc-nd/4.0/).

2666-061X/19971

https://doi.org/10.1016/j.asmr.2020.02.001 
Switzerland, which includes direct medical costs as well as worker compensation claims; the latter is paid in $64 \%$ of cases, with a mean duration of 97 sick leave days. ${ }^{1}$ Both nonoperative and operative treatments of $\mathrm{RC}$ tears can lead to significant improvements over time. ${ }^{2,3}$ Nontraumatic degenerative RC tears may be primarily managed in a nonoperative manner. ${ }^{2-5}$ The outcome of nonoperative treatment within the first 3 months has a prognostic value extending up to 5 years. ${ }^{6}$ However, up to $25 \%$ of these patients undergo surgery within 1 and 5 years because of unsatisfactory outcome. ${ }^{4}$ Traumatic and massive tears may benefit from early surgery, with arthroscopic rotator cuff repair (aRCR) providing substantial pain relief and increasing shoulder function in affected patients. ${ }^{7}$

Triggered by rising health care costs, health economic evaluations have become part of the assessment of surgical interventions in orthopaedics. ${ }^{8}$ Yet cost-utility analyses of upper-extremity interventions are rare and mostly based on hypothetical scenarios and modeled data derived purely from the literature. ${ }^{9}$ There is a lack of using real-world data-collected from individual electronic health records of patients, claims and billing activities, disease registries, etc. - to illustrate the relationship between patient benefit reported in the form of patient-reported outcome measures (PROMS) and costs in a real-world setting. These data are essential to assess the value of health care for society. ${ }^{10}$ In Switzerland, there is no explicit threshold prescribed for society and its willingness to pay for a certain amount of value: for example, costs involved for 1 additional quality-adjusted life year (QALY). Nevertheless, the threshold of 100,000 CHF/QALY has been recommended for high-income countries. ${ }^{11}$

The purpose of this study was to assess the change in quality of life (QOL) and costs for patients with RC tears after aRCR compared with continued nonoperative management using real-world evidence. The hypothesis was that QOL would substantially improve after surgery, resulting in an acceptable cost-utility ratio for aRCR patients treated at a specialized Swiss orthopaedic hospital.

\section{Methods}

\section{Design}

A health economic investigation was performed to assess patient benefits and costs associated with aRCR compared with nonoperative management of RC tears using a before-and-after-surgery comparison (pre-post design). The study protocol was approved by the Cantonal Ethics Committee of Zurich, Switzerland, and was registered at ClinicalTrials.gov (NCT01954433).

\section{Patients}

Patients aged $\geq 18$ years who were diagnosed with a partial or complete RC tear indicated for aRCR and provided written informed consent were eligible for study inclusion. All consecutive patients with RC tears of traumatic origin as well as patients with degenerative tears were included. For the latter, an unsuccessful nonoperative approach (i.e., after $\geq 3$ months of physiotherapy in combination with anti-inflammatory medication) was seen as an indication for surgical repair. Patients with irreparable tears were excluded. Additional exclusion criteria included general medical contraindications to surgery, any revision operation, tumor/malignancy, any disease process that would preclude accurate evaluation (e.g., neuromuscular, psychiatric, or metabolic disorder), recent history of substance abuse, legal incompetence, pregnancy, or participation in any other study that could influence the results of the present study. Eligible patients were consecutively enrolled until a total of 150 patients were operated and did not fulfill any exclusion criteria or drop out within 2 weeks after surgery. Baseline parameters included patient sociodemographic data, general health status, anamnesis, and shoulder condition. RC tears (partial or full-thickness tear and involved tendons) were initially assessed using magnetic resonance imaging (MRI) and confirmed intraoperatively according to a modified Patte classification. ${ }^{12}$ Preoperative MRI was also used to grade the extent of RC fatty infiltration. ${ }^{13}$

\section{Operative Management and Rehabilitation}

All aRCR patients were inpatients at a specialized Swiss orthopaedic hospital. The surgical procedure was performed according to standard internal and international guidelines in a beach-chair position under general anesthesia. ${ }^{14}$ Any repair procedure was carried out or directly supervised by 1 of 7 experienced specialist shoulder surgeons performing $>50$ aRCRs annually. After diagnostic arthroscopy, the biceps tendon was tenotomized when required, and for most patients, standard acromioplasty was performed. The ruptured tendons were mobilized until they could be repositioned on the original footprint with the least possible tension. All surgeons used knotless suture bridge fixation, typically with 2 medial and 2 lateral anchors for the supraspinatus. Additional medial anchors for the subscapularis and infraspinatus were used as needed. Rotator cuff tear patterns and associated pathologies, operative details including repair techniques for each involved tendon, and additional procedures (i.e., acromioclavicular resection, acromioplasty, capsulotomy, biceps treatment, and superior labrum anterior to posterior treatment) as well as intraoperative complications were recorded immediately after surgery.

All patients began a standard 3-phase postoperative physiotherapy scheme for their operated shoulder, which included 6 weeks of immobilization with an abduction pillow and passive mobilization, followed by 


\section{Recruitment}

\section{Patients with diagnosed rotator cuff tear enrolled between November 2013 and March 2015 (177 patients)}

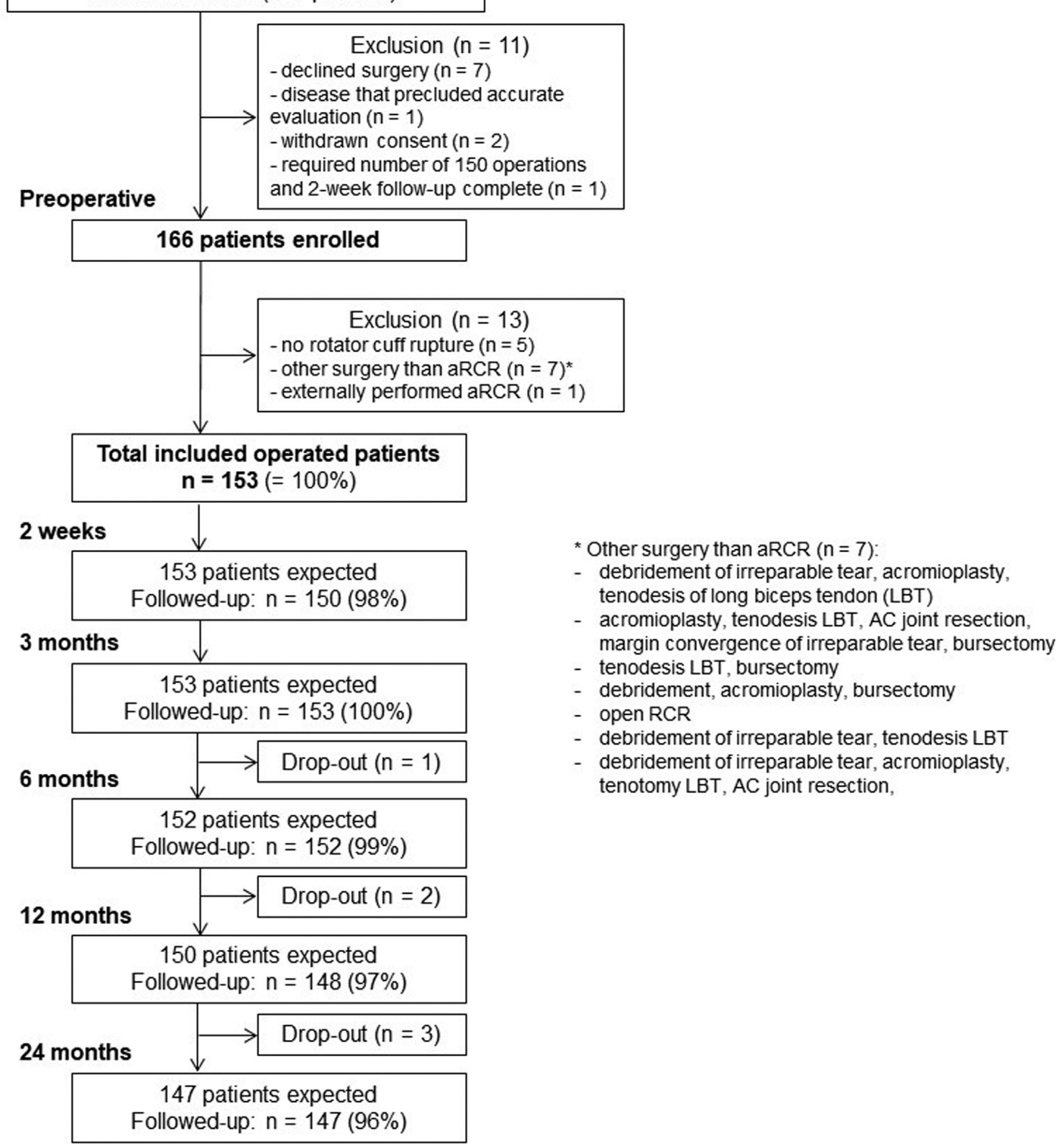

Figure 1. Study flow. Patient recruitment and follow-up flowchart. 
Table 1. Baseline Characteristics

\begin{tabular}{|c|c|c|c|c|c|c|}
\hline \multirow[b]{2}{*}{ Characteristic } & \multicolumn{2}{|c|}{ All aRCR Patients } & \multicolumn{2}{|c|}{ Trauma-OP } & \multicolumn{2}{|c|}{ Degen-OP } \\
\hline & $\mathrm{n}(\%)$ & Mean (SD) & $\mathrm{n}(\%)$ & Mean (SD) & $\mathrm{n}(\%)$ & Mean (SD) \\
\hline Patients & 153 & & 92 & & 61 & \\
\hline Age at surgery $(\mathrm{y})$ & & $56.9(8.2)$ & & $55.4(8.1)$ & & $59.2(8.0)$ \\
\hline Male sex & $97(63)$ & & $66(72)$ & & $31(51)$ & \\
\hline Comorbidities & $54(35)$ & & $23(25)$ & & $31(51)$ & \\
\hline \multicolumn{7}{|l|}{ Duration of shoulder problems } \\
\hline$<1 \mathrm{mo}$ & $22(15)$ & & $21(21)$ & & $1(2)$ & \\
\hline 6 mo to $1 \mathrm{y}$ & $33(22)$ & & $17(18)$ & & $16(26)$ & \\
\hline$>1 \mathrm{y}$ & $30(20)$ & & $8(9)$ & & $22(36)$ & \\
\hline Working & $110(72)$ & & $75(82)$ & & $35(57)$ & \\
\hline Workload reduced before aRCR & $31(28)$ & & $28(37)$ & & $3(9)$ & \\
\hline \multicolumn{7}{|l|}{ Nonoperativeerative treatment } \\
\hline Steroid infiltration & $49(32)$ & & $20(22)$ & & $29(48)$ & \\
\hline SSC & $7(5)$ & & $7(8)$ & & & \\
\hline SSP & $85(56)$ & & $41(45)$ & & $44(72)$ & \\
\hline SSP and ISP & $24(16)$ & & $19(21)$ & & $5(8)$ & \\
\hline SSP and SSC & $26(17)$ & & $17(18)$ & & $9(15)$ & \\
\hline SSP and SSC and ISP & $11(7)$ & & $8(9)$ & & $3(5)$ & \\
\hline \multicolumn{7}{|l|}{ Tear severity ${ }^{*}$} \\
\hline Partial tear & $29(18)$ & & $10(11)$ & & $19(28)$ & \\
\hline Single full tear & $71(44)$ & & $39(42)$ & & $32(48)$ & \\
\hline Two or 3 tendons (only 1 full) & $29(18)$ & & $20(22)$ & & $9(13)$ & \\
\hline Massive tear & $31(19)$ & & $24(26)$ & & $7(10)$ & \\
\hline \multicolumn{7}{|l|}{ Fatty infiltration of involved RC muscles ${ }^{\dagger}$} \\
\hline Stage 0 & $95(62)$ & & $58(65)$ & & $37(57)$ & \\
\hline EQ-5D-5L utility index (Germany) & 152 & $0.71(0.23)$ & 92 & $0.72(0.21)$ & 60 & $0.69(0.26)$ \\
\hline EQ-VAS $(0=$ worst, $100=$ best $)$ & 153 & $70(18)$ & 92 & $72(16)$ & 61 & $68(19)$ \\
\hline
\end{tabular}

aRCR, arthroscopic rotator cuff repair; degen-OP, aRCR patients with degenerative rotator cuff tears; EQ-VAS, EQ-5D General Health Visual Analogue Scale; ISP, infraspinatus; RC, rotator cuff; SD, standard deviation; SSC, subscapularis; SSP, supraspinatus; trauma-OP, aRCR patients with traumatic rotator cuff tears.

${ }^{*}$ Gerber et al. ${ }^{27}$

${ }^{\dagger}$ Fuchs et al. ${ }^{13}$; using magnetic resonance imaging: stage 0 , normal muscle; stage 1 , some fatty streaks; stage $2,<50 \%$ fatty muscle atrophy.

active mobilization and coordination training for 4 weeks, and finally specific progressive resistance exercises.

\section{Patient-Reported and Clinical Outcomes}

The primary outcome for this study was the change in QOL and costs of aRCR. Patients were followed up at 7 time points throughout the study period: at enrollment and at the time of hospital admission shortly before surgery (both occurring within the l-year preop period), and at 2 weeks, 3 months, 6 months, and 1 and
2 years after surgery (e-Supplement 1 ). Work status and PROMS were documented at all 7 time points, whereby patients completed questionnaires covering QOL, shoulder function, employment conditions, return to work, and activities of daily living. Questionnaires were completed in electronic form either on a tablet computer at the clinic or at home after receiving an email invitation; patients preferring to complete the questionnaires at home on a paper form returned their responses by mail. QOL was assessed using the European Quality of Life 5 Dimensions 5 Level (EQ-5D-5L) 
Figure 2. Utility index (EQ5D-5L) over time. Quality of life (utility index) for arthroscopic rotator cuff repair patients as measured by the European Quality of Life 5 Dimensions 5 Level (EQ-5D-5L) questionnaire at each followup time point (range -0.66 to 1.0; minimal clinically important difference [MCID] = 0.074 points). ${ }^{23}$ The horizontal dashed line indicates the utility index for the health state we assumed patients would maintain throughout the entire follow-up period if they had not undergone surgery.

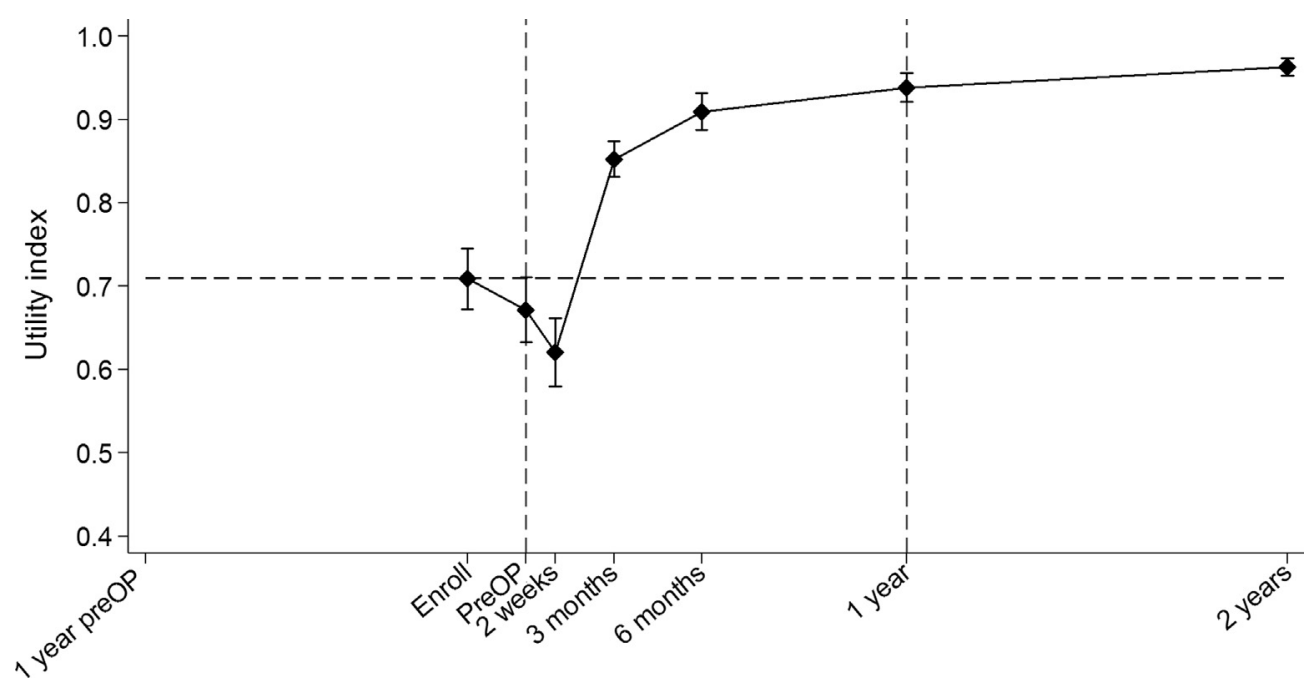

questionnaire. ${ }^{15}$ The EQ-5D-5L responses were converted into utilities (ranging from -0.66 [lowest QOL] to 1 [highest QOL]) ${ }^{15}$ using the EQ-5D-5L value set for Germany. ${ }^{16}$ The EQ-5D is valid and reliable and the most frequently used instrument to evaluate health states using utilities and to calculate quality-adjusted life years (QALYs). ${ }^{17}$ Patient-reported shoulder function was assessed using the Oxford Shoulder Score $(\mathrm{OSS})^{18}$ and subjective shoulder value (SSV). ${ }^{19}$

Routine clinical examinations were performed by physicians at enrollment as well as the 3-and 6-month postoperative time points, and by a study assistant at the time of hospital admission shortly before surgery. Examinations included shoulder range of motion and muscle strength in $90^{\circ}$ abduction, overall shoulder function as measured by the Constant Score (CS), ${ }^{20}$ and occurrence of postoperative complications. ${ }^{21}$

\section{Cost and Productivity Data}

Direct medical costs (all medical expenses including aRCR-related costs) and productivity data of aRCR patients were collected for 3 time periods: (1) the year before surgery (preop period), (2) surgery and the consecutive first postoperative year, and (3) the second postoperative year (e-Supplement 1). In a similar manner, the costs and productivity data for patients during nonoperative management were considered in the year before enrollment as well as the first and second years after enrollment. Sixteen major Swiss health and accident insurance companies provided direct medical inpatient and outpatient cost data extracted from their claims database. Costs included alldiagnosis direct medical costs of all treatments, complications, drugs, and consultations covered by the mandatory health and accident insurance companies, pertaining to the inpatient and outpatient sector for each patient across all hospitals and other providers. All inpatient costs represent $45 \%$ of the total inpatient costs in the Swiss health system, and therefore, these costs were adjusted by dividing the provided inpatient costs by 0.45 .

Productivity losses due to shoulder complaints resulting from a RC tear only were assessed at

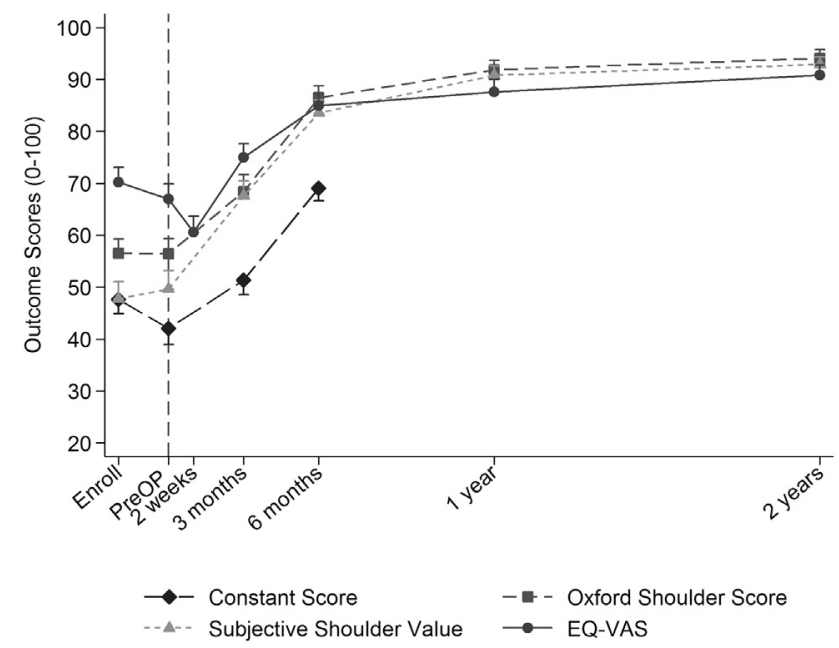

Figure 3. Shoulder function and quality of life over time. Outcome scores for arthroscopic rotator cuff repair patients are shown at each follow-up time point. Clinical examinations for the Constant Score (range 0 to 100; minimal clinically important difference $[\mathrm{MCID}]=8.3$ points $)^{28}$ were performed up to the 6-month follow-up and patient-reported outcomes up to 2 years after surgery. The original scale of the Oxford Shoulder Score ranging from 0 to 48 was adapted to 0 to 100 for presentation purposes (MCID adapted for range 0 to $100=$ 11.0 points). ${ }^{28}$ Subjective shoulder value: Subjective evaluation of shoulder function by the patient in relation to normal shoulder function (range $0 \%$ to $100 \%$ ). EQ-VAS = EQ-5D General Health Visual Analogue Scale (range 0 to 100 points; MCID $=7.18$ points) ${ }^{28}$ 
Table 2. Direct medical costs and productivity losses in Swiss Francs (CHF)

\begin{tabular}{|c|c|c|c|c|c|c|}
\hline & $\mathrm{n}$ & $\begin{array}{l}\text { Preoperative } \\
\text { Year (CHF) }\end{array}$ & $\begin{array}{c}\text { First Postoperative } \\
\text { Year (CHF) }\end{array}$ & $\begin{array}{c}\text { Second Postoperative } \\
\text { Year (CHF) }\end{array}$ & $\mathrm{n}^{*}$ & $\begin{array}{l}\text { Incremental } \\
\text { Costs }(\mathrm{CHF})\end{array}$ \\
\hline \multicolumn{7}{|l|}{$\begin{array}{c}\text { Operated } \\
\text { (aRCR) } \\
\text { patients }\end{array}$} \\
\hline $\begin{array}{l}\text { Direct medical } \\
\text { costs }\end{array}$ & 130 & $5,499(6,167)$ & $17,116(10,058)$ & $4,226(7,998)$ & 116 & $5,009(7,139)$ \\
\hline $\begin{array}{l}\text { Inpatient cost } \\
\text { data }\end{array}$ & 130 & $963(3,480)$ & $12,129(8,580)$ & $1,872(6,152)$ & & \\
\hline $\begin{array}{l}\text { Productivity } \\
\text { loss }\end{array}$ & 88 & $42,001 \quad(44,067)$ & $25,565(23,188)$ & $5,415(14,523)$ & & \\
\hline \multicolumn{7}{|l|}{$\begin{array}{l}\text { Trauma-OP } \\
\text { patients }\end{array}$} \\
\hline $\begin{array}{l}\text { Direct medical } \\
\text { costs }\end{array}$ & 77 & $4,313(5,569)$ & $14,843(4,581)$ & $1,531(3,406)$ & 66 & $3,704(4,388)$ \\
\hline $\begin{array}{l}\text { Productivity } \\
\text { loss }\end{array}$ & 59 & $49,547(45,554)$ & $28,325(24,595)$ & $4,438(11,471)$ & & \\
\hline \multicolumn{7}{|l|}{$\begin{array}{l}\text { Degen-OP } \\
\text { patients }\end{array}$} \\
\hline $\begin{array}{l}\text { Direct medical } \\
\text { costs }\end{array}$ & 53 & $7,221(6,626)$ & $20,418(14,197)$ & $8,140(10,742)$ & 50 & $6,732(9,420)$ \\
\hline $\begin{array}{l}\text { Inpatient cost } \\
\text { data }\end{array}$ & 53 & $1,408(4,428)$ & $14,264(12,722)$ & $4,080(9,043)$ & & \\
\hline $\begin{array}{r}\text { Outpatient } \\
\text { cost data }\end{array}$ & 53 & $5,813(4,180)$ & $6,154(3,778)$ & $4,060(3,707)$ & & \\
\hline $\begin{array}{l}\text { Productivity } \\
\text { loss }\end{array}$ & 29 & $26,649(37,030)$ & $20,425(19,686)$ & $7,296(19,211)$ & & \\
\hline
\end{tabular}

NOTE. Data are presented as mean (standard deviation).

aRCR, arthroscopic rotator cuff repair; degen-OP, aRCR patients with degenerative rotator cuff tear; trauma-OP, aRCR patients with traumatic rotator cuff tear.

*Patients with complete cost data and corresponding quality-adjusted life years.

enrollment, at the time of hospital admission shortly before surgery, and at 3 months, 6 months, and 1 and 2 years after surgery using the Work Productivity and Activity Impairment Questionnaire - Specific Health Problem Version 2.0 (WPAI-SHP) ${ }^{22}$ consisting of 6 questions on absenteeism (absence from work) and presenteeism (reduced productivity when at work) during the last 7 days. Additional work-related data included (1) the number of hours usually worked per week, (2) whether the level of employment had been reduced due to the $\mathrm{RC}$ tear, (3) the duration of absence from work after surgery, and (4) the current monthly personal income in brackets of 2,000 CHF to $\geq 16,000$ CHF.

\section{Statistical Analysis}

The power analysis considered a predetermined sample size of 150 operated patients to detect a clinically important change in QOL of $0.074^{23}$ in this group. This calculation was based on a standard deviation of

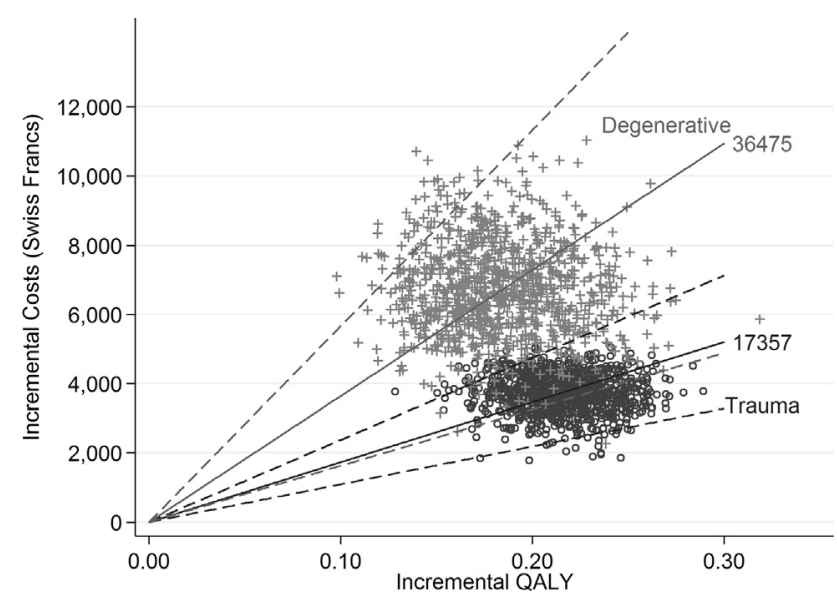

Figure 4. Cost-effectiveness plot using direct medical costs. Incremental cost-effectiveness ratio (ICER) for patients with traumatic and degenerative rotator cuff tears (black and grey bold lines, respectively) and the 95\% confidence interval (dashed lines). Incremental costs, direct medical costs; QALY, quality-adjusted life years 
0.30 , a significance level of 0.05 , and a power of $80 \%$ while considering a maximum loss to follow-up of $10 \%$.

All data were entered into a web-based electronic database using REDCap Software 6.16.5 (Vanderbilt University, Nashville, TN $)^{24}$ and exported for analysis into Intercooled Stata 14.2 (StataCorp, College Station, TX).

Baseline patient sociodemographic data and RC tear diagnostic, functional, and operative parameters were tabulated using standard descriptive statistics for all operated patients and separately for traumatic aRCR (trauma-OP) (classified by the accident date documented in the local clinic patient information system) and degenerative aRCR (degen-OP) patients. The change of QOL was analyzed using a paired $t$ test and reported as the mean with its $95 \%$ confidence interval (95\% CI). QALYs were calculated by multiplying utilities with the length of time over which health state was experienced. The assumption was that the health state between 2 assessment points was equal to the mean of the utilities recorded at these points. For the base case, it was assumed that if patients had not undergone surgery, they would have maintained their preoperative health state throughout the follow-up period under evaluation.

Annual direct medical costs (all-diagnosis costs including aRCR-related costs) were calculated for each 1 -year period. The incremental cost-effectiveness ratio (ICER) was calculated by dividing the difference in annual costs (postoperative period minus preop period) by the difference in QALYs. Results were calculated for the entire sample as well as for trauma-OP and degenOP patient subgroups. The $95 \%$ CIs of costs and ICER were calculated using nonparametric bootstrapping methods. $^{25}$

Productivity losses for the patient population, which had a labor type pattern representative of RC tear patients in Switzerland, were calculated by multiplying the accumulated productivity losses due to healthrelated (i.e., shoulder-specific) absenteeism and presenteeism $^{26}$ with annual earnings. These losses were extrapolated over the time between 2 questionnaires. For example, patients reporting to be still out of work 3 months after surgery who then reported working at $50 \%$ of their full-time level of employment 6 months after surgery were considered as working at $25 \%$ of their full-time level of employment between 3 and 6 months after surgery. Costs were reported in $2017 \mathrm{CHF}$ (conversion rate to USD, 1.03; to Euro, 0.85; to British pound, 0.76). Current standards for performing health economic evaluations were applied. ${ }^{8}$

The changes of all outcome parameters from baseline to each follow-up assessment were analyzed using generalized linear mixed models to account for repeated measurements. The relationship between shoulder 


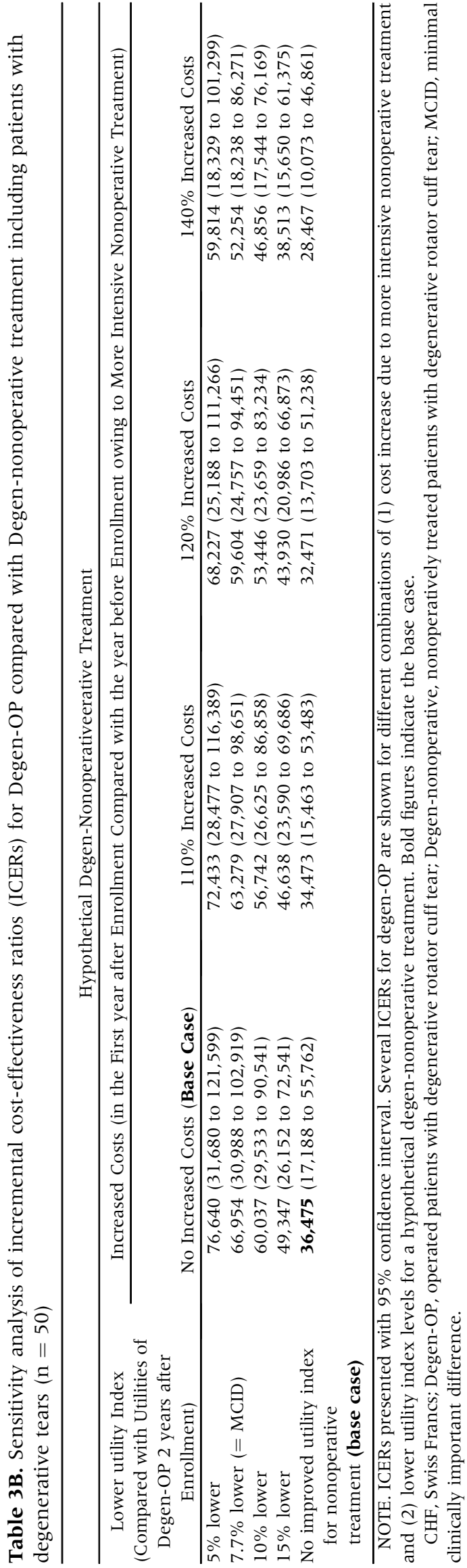

function (CS, SSV, OSS) and QOL utility index over time was explored with scatter plots as well as regression analysis, while adjusting for the baseline index.

\section{Sensitivity Analysis}

One major assumption in the primary analysis (base case) of this study was that the QOL index of patients continuing a hypothetical nonoperative management would remain constant over time. However, 2 recent meta-analyses highlighted that patients with degenerative tears who undergo intensified physiotherapy instead of surgery would improve their QOL. ${ }^{2,3}$ Even though these patients would not achieve the same QOL levels as operated patients after 2 years of follow-up, the difference would not exceed the minimal clinically important difference (MCID). Therefore, a sensitivity analysis was conducted to simulate an improvement in QOL within the nonoperative treatment setting for the whole patient group (hypothetical nonoperative group) and for patients with degenerative tears (hypothetical degen-nonoperative group).

In addition to the base case (i.e. no improvement in QOL after nonoperative management), a linear increase in QOL was simulated from the time point of a hypothetical more intensive nonoperative treatment until the 2-year follow-up using 4 values of mean utility of the aRCR group (i.e., all operated patients): $-5 \%$; $-7.7 \%$ (corresponding to the MCID of -0.07 utilities); $-10 \%$; and $-15 \%$ (e-Supplement 2 ). In addition to the base case (i.e., no increased costs), hypothetically increased direct medical costs in the nonoperative and degen-nonoperative group due to more intensive nonoperative management in the year after enrollment were also considered, assuming $110 \%, 120 \%$, or $140 \%$ of the documented costs of the preop year for the first year after enrollment. The costs in the second year after enrollment, in turn, were considered similar to the year before enrollment.

\section{Results}

\section{Patient Enrollment and Baseline Characteristics}

Between November 2013 and March 2015, 177 patients were enrolled (Figure 1). Twenty-four patients $(14 \%)$ were excluded because of ineligibility (including 7 who declined aRCR surgery), and 6 patients $(4 \%)$ dropped out during the study. The final sample included 92 traumatic $(60 \%)$ and 61 degenerative tears, and the majority $(94 \%)$ were hospitalized for 3 to 4 days. Table 1 summarizes the baseline characteristics, PROMS, and clinical outcomes for all aRCR patients as well as the subgroups, trauma-OP and degen-OP.

\section{Patient-Reported and Clinical Outcomes}

From a baseline value of 0.71 , the EQ-5D utility index dropped after surgery, but improved substantially by a 
Figure 5. Return-to-work rates over time. Kaplan-Meier curve showing the percentage of patients returning to work after arthroscopic rotator cuff repair; $\mathrm{m}$, months; $\mathrm{y}$, years.

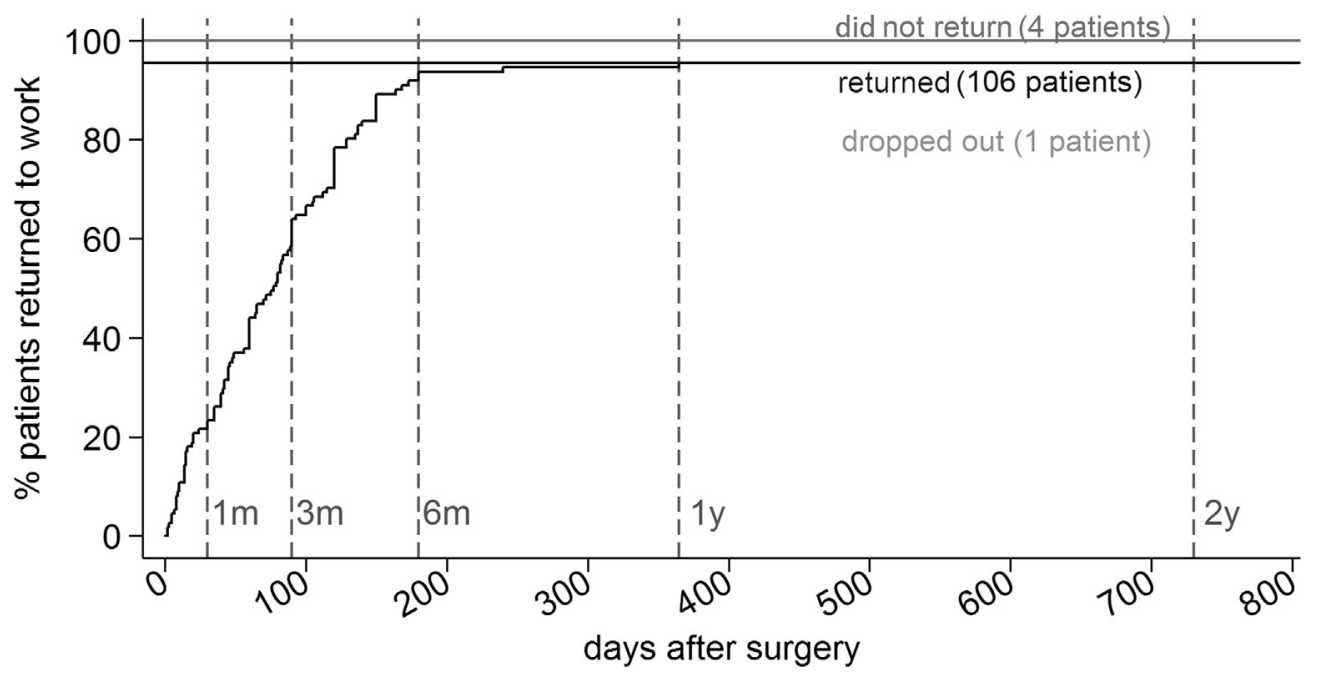

mean of 0.26 for aRCR patients at the end of the first and second postoperative years $(P<.001$; Figure 2$)$; similar observations were made for the trauma-OP and degen-OP subgroups (e-Supplement 3). All other baseline PROMS also improved substantially for the aRCR as well as trauma-OP and degen-OP groups until 1 year after surgery and remained at that level in the second postoperative year $(P<.001$; Figure 3 and eSupplement 3).

\section{Cost-Utility Analysis}

Direct cost data were obtained for 130 patients (85\%) who were insured by major Swiss insurance companies. Mean direct costs increased from 5,499 $\mathrm{CHF}(5,664$ USD) in the year before surgery (comprising mainly outpatient costs) to $17,116 \mathrm{CHF}(17,629$ USD) in the first year after surgery (comprising the costs of surgery), with a shift toward increasing inpatient costs (Table 2); this was followed by a decrease to 4,226 CHF $(4,353$ USD) in the second postoperative year, which was below the mean cost incurred before surgery. The same trend was seen for the trauma-OP and degen-OP subgroups, although second postoperative year costs were higher than preoperative costs for the latter.

The ICER for all aRCR patients was 24,924 CHF/ QALY (95\% CI, 16,742 to 33,$106 ; 25,672$ USD/QALY). The corresponding ICER for the trauma-OP group was $17,357 \mathrm{CHF} / \mathrm{QALY}$ (95\% CI 10,951 to 23,$763 ; 17,878$ USD/QALY) and 36,475 CHF/QALY (95\% CI 16,301 to 56,$648 ; 37,569$ USD/QALY) for the degen-OP group (Figure 4).

The sensitivity analyses resulted in ICERs ranging from 50,712 to $19,237 \mathrm{CHF} / \mathrm{QALY}(52,233$ to 19,814 USD/QALY) for the whole patient group (Table $3 \mathrm{~A}$ ) and 76,640 to $28,467 \mathrm{CHF} / \mathrm{QALY}(78,939$ to $29,321 \mathrm{USD} /$ QALY) for patients with degenerative tears (Table $3 B$ ).

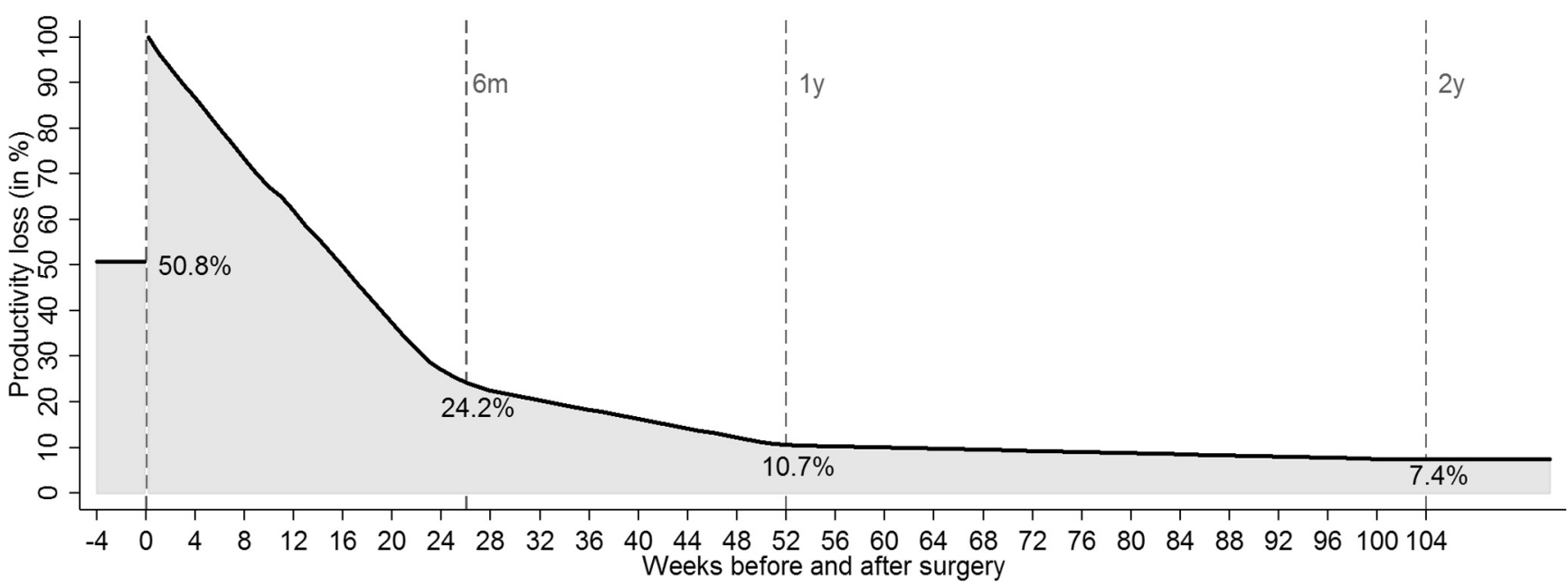

Figure 6. Productivity losses over time. Productivity losses of all arthroscopic rotator cuff repair patients $(\mathrm{N}=97)$ until 2 years after surgery. The horizontal line between -4 and 0 weeks indicates the preoperative period. 


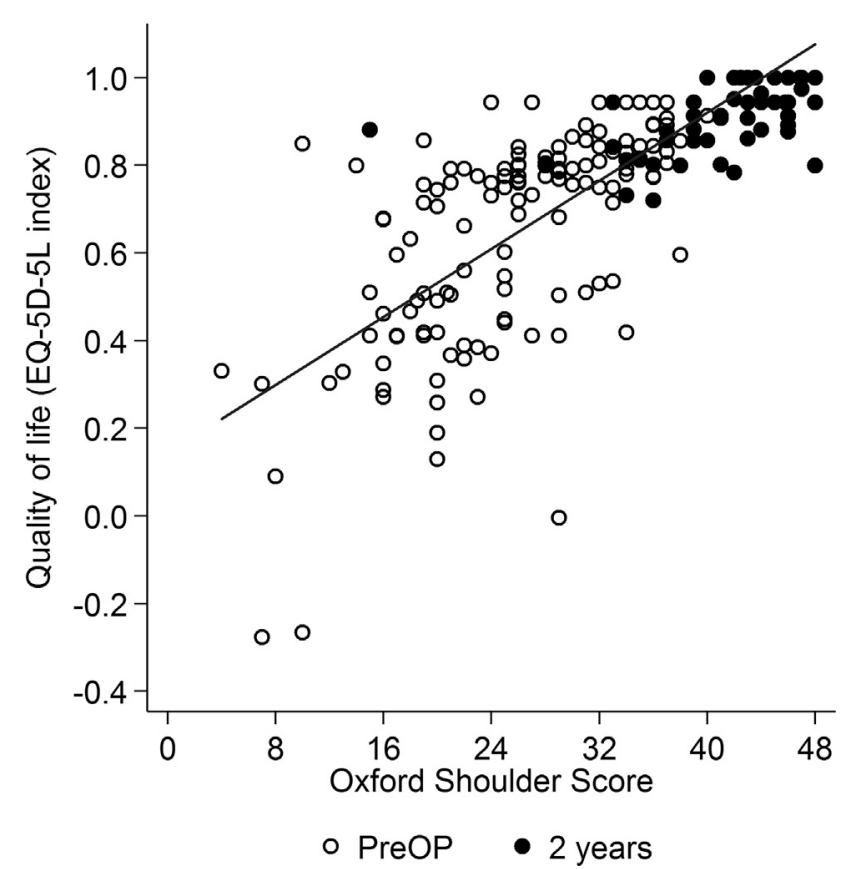

Figure 7. Association between quality of life and shoulder function over time. Each data point represents 1 patient preoperatively or 2 years after surgery. Scatter plot showing the association between quality of life (indicated by the European Quality of Life 5 Dimensions 5 Level [EQ-5D-5L] utility index; range 0.0 to 1.0 ; minimal clinically important difference $[\mathrm{MCID}]=0.074)^{23}$ and the Oxford Shoulder Score (OSS; range 0 to 48 ; $\mathrm{MCID}=4.7$ and 6.0 for shoulder pain and function, respectively) ${ }^{29}$ before and 2 years after surgery. The regression line indicates the association between quality of life and OSS at the preoperative time point.

Among a total of 110 working patients in the aRCR group, 31 patients $(28 \% ; 37 \%$ of 75 trauma-OP patients and $9 \%$ of 35 degen-OP patients) reduced their work activity either preop or before study enrollment. Preop productivity losses for 97 working patients with complete data were $56 \%$ and $40 \%$ of the work activity level for trauma-OP and degen-OP patients, respectively; these losses peaked after surgery. Operated patients returned to work on average after 77 days (Figure 5). Sixteen weeks after surgery, productivity losses decreased below preop levels (Figure 6). Mean productivity losses for the aRCR group were 42,001 CHF $(43,261$ USD) per patient in the year before surgery and decreased to $5,415 \mathrm{CHF}(5,577$ USD) $\leq 2$ years after surgery (Table 2).

The OSS, SSV, and CS were significantly associated with the EQ-5D index at both preop and 2-yearpostop time points $(P<.001$; Figure 7 ; EQ-5D index vs SSV and CS scatter plots not shown). The coefficients of determination $\left(R^{2}\right)$ were $0.52,0.46$, and 0.42 for the OSS, SSV 2 years postop, and CS 6 months postop.

\section{Discussion}

For patients who underwent aRCR for traumatic and degenerative tears, there was a clinically relevant improvement in quality of life from 3 months to 2 years after surgery compared with the preop state, which was associated with improved shoulder function. The costutility ratio of aRCR was estimated at 24,924 CHF/ QALY, which clearly falls below the suggested threshold of 100,000 CHF/QALY for high-income countries. ${ }^{11}$

This study presents real-world data for a consecutive series of aRCR patients treated at a large orthopaedic tertiary hospital. In contrast, the most recently published health economic studies are based on modeling techniques using estimated cost data. ${ }^{30-34}$ For the vast majority of patients, standard nonoperative management failed, and based on the judgment of the experienced shoulder specialists, a different response to the reported shoulder problems was to be expected with surgery. Therefore, randomization of these patients between aRCR and intensive physical therapy was considered unethical and infeasible. The pre-post study design of the current study is a suitable approach given the circumstances of the clinical setting.

QOL as documented by the EQ-5D-5L utility index improved significantly, by 0.26 points. This is well above the estimated MCID of $0.074,{ }^{23}$ which was calculated from 11 patient groups not specifically including aRCR patients. The existing data on change in QOL in upperextremity orthopaedic disorders using the EQ-5D-5L instrument are very limited. ${ }^{17}$ The few studies reporting EQ-5D-5L utility indices for aRCR patients show consistent improvement in QOL of 0.20 and 0.19 at 1 and 2 years after surgery. ${ }^{33,35}$ Furthermore, there is a QALY gain of 1.34 at 2 years after aRCR, ${ }^{36}$ as well as a lifetime QALY gain of either $3.43^{35}$ or $11.73 .{ }^{31}$

The ICER of aRCR patients was 24,924 CHF/QALY 2 years after surgery from a health care system perspective (base case). In the sensitivity analysis, the resultant ICER of 47,820 CHF/QALY for aRCR still falls below the cost-effectiveness threshold, even when considering a conservative assumption (QOL values: for the hypothetical nonoperative group, 5\% less compared with aRCR patients; costs: slightly increased costs of $110 \%$ for more intensive nonoperative treatment compared with the year before enrollment). Two independent studies that compared aRCR versus nonoperative management found similar ICERs of 15,500 USD (15,106 CHF) and 30,001 GBP (39,501 CHF) per QALY, respectively. ${ }^{31,36}$ Yet most of the work already published applied modeling techniques using estimated utility and cost data extracted from the literature. . $^{30-32,34}$ Studies reporting on primary health economic data are rare. A prospective cost-utility study analyzed patients who underwent open or mini-open RC tear repair, ${ }^{35}$ and 3 prospective health economic investigations 
compared aRCR with physiotherapy or open RC repair ${ }^{5,33,36}$ in patients aged $>50$ years with degenerative full-thickness tears. Two studies were conducted from a health care system perspective using direct medical costs for ICER calculation. ${ }^{33,35}$ The remaining studies considered the societal perspective by analyzing productivity losses due to sick leave, ${ }^{5,36}$ but either compared aRCR with open repair ${ }^{36}$ or did not report an ICER. ${ }^{5}$ A comparison of results across studies requires consideration of the case mix. Traumatic RC tear patients included in the current study were younger, less affected by comorbidities, and more often employed than patients affected by degenerative tears. These patient groups generate varying amounts of direct medical costs and productivity losses, which are likely related to their different demographic and health profiles.

Shoulder problems generated substantial preoperative productivity losses, with $80 \%$ of working patients having impairments, particularly those in the traumaOP group, possibly owing to the presence of more severe RC lesions. Although return to work and increasing workloads were attained after an average of 77 postoperative days, it is unlikely that aRCR patients would have achieved a better working status if they had not undergone surgery. Nevertheless, it is not possible to speculate on what their status would have been, and therefore the associated costs were not included in the ICER calculation. Furthermore, the ICER considers only 2 years of follow-up, although the treatment effect of aRCR is expected to last far longer. Previous cost-utility studies considered the patient's remaining lifetime and noted good to excellent results for $>90 \%$ of RCR patients, as well as low long-term revision rates at postoperative follow-ups ranging from 2 to 10 years. $^{30,35}$ Those studies assumed that expenses in the first postoperative year capture the majority of costs associated with RCR, and that fewer downstream costs would follow. Further investigation is required to assess whether a more favorable ICER would be achieved for aRCR with the studied patient collective over a longterm follow-up extending beyond 2 years.

\section{Limitations}

One main study limitation is the lack of a randomized study design. ${ }^{8}$ However, a pre-post design, which has already been applied elsewhere, ${ }^{37}$ was considered most feasible in this clinical setting; patients with traumatic tears or persisting pain after nonoperative management mainly consult specialty tertiary referral hospitals such as our clinic. With only 7 patients who declined surgery and had baseline characteristics poorly comparable to the aRCR patients, it proved inadequate to build an appropriate control group. Such an obstacle was encountered in another large cost-utility study owing to a high rate of crossovers to surgery $(77 \%)$ within 2 years after enrollment, ${ }^{36}$ as well as another more recent study with a 10 -year follow-up period $(27 \%)$ from the group of Moosmayer. ${ }^{38}$ The high proportion of patients with previously unsuccessful nonoperative treatment contributed to the difficulties that were encountered in achieving a sizable comparison group who would have undergone continued and more intensive nonoperative care. By using preop data for comparative purposes, the strong assumption was that aRCR patients would remain in their same condition without surgery. With the sensitivity analyses, alternative scenarios were applied based on previous reports, ${ }^{2,3}$ which considered successful nonoperative management for the whole patient group as well as for patients with degenerative tears. However, it is still unclear how likely these scenarios truly apply to the study patients. Furthermore, it must be considered that only all-diagnoses direct medical costs were available, which included costs of other health-related comorbidities or complications due to aRCR. Because of the pre-post study design, the use of this comprehensive cost data should nonetheless have limited impact on incremental costs, and any cost due to potential side effects of surgery can also be examined. Lastly, the results of this study need to be considered in terms of the local surgical routine undertaken at our clinic, and may differ in other institutions located particularly outside Switzerland.

\section{Conclusions}

For RC patients treated at a specialized Swiss orthopaedic clinic, aRCR is a cost-effective intervention associated with clinically relevant improvement in QOL up to 2 years after repair compared with prior nonoperative management.

\section{Acknowledgments}

Support for this research was provided by Schulthess Klinik and Winterthur Institute of Health Economics. Mäxi Foundation, Bank Vontobel Charitable Foundation and the Winterthur Network of Health Economics provided financial resources. Clinical trial registration: WwW.ClinicalTrial.gov Identifier: NCT01586351. Institutional Review Board/Ethics Committee approval was granted by the following institution: Cantonal Ethics Committee of Zurich, Stampfenbachstrasse 121, 8090 Zurich. Approval for the study (Nr. 2013-0381) was granted on 30.09.2013. The authors thank M. Wilhelmi Ph.D., medical writer at the Schulthess Klinik, for the copyediting of this manuscript, and the insurance companies Aquilana, Assura, Attupri, AXA Winterthur, Baloise, Concordia, CSS, Groupe Mutuel, Helsana, KPT, ÖKK, Sanitas, SUVA, SWICA, Visana, and Zurich Insurance Group for providing direct medical cost data. 


\section{References}

1. Collective for the Statistics of Accident Insurance (Swiss Federal Law on Accident Insurance [SSUV-UVG]). [Rotator cuff tendon injury]. SSUV UVG Pool 2009-2012 2018 April 23. Version: 1.03.01. In German.

2. Piper CC, Hughes AJ, Ma Y, Wang H, Neviaser AS. Operative versus nonoperative treatment for the management of full-thickness rotator cuff tears: A systematic review and meta-analysis. J Shoulder Elbow Surg 2018;27: 572-576.

3. Ryosa A, Laimi K, Aarimaa V, Lehtimaki K, Kukkonen J, Saltychev M. Surgery or conservative treatment for rotator cuff tear: A meta-analysis. Disabil Rehabil 2017;39: 1357-1363.

4. Moosmayer S, Lund G, Seljom US, et al. Tendon repair compared with physiotherapy in the treatment of rotator cuff tears: A randomized controlled study in 103 cases with a five-year follow-up. J Bone Joint Surg Am 2014;96: 1504-1514.

5. Kukkonen J, Joukainen A, Lehtinen J, et al. Treatment of nontraumatic rotator cuff tears: A randomized controlled trial with two years of clinical and imaging follow-up. J Bone Joint Surg Am 2015;97:1729-1737.

6. Boorman RS, More KD, Hollinshead RM, et al. What happens to patients when we do not repair their cuff tears? Five-year rotator cuff quality-of-life index outcomes following nonoperative treatment of patients with full-thickness rotator cuff tears. J Shoulder Elbow Surg 2018;27:444-448.

7. Duncan NS, Booker SJ, Gooding BW, Geoghegan J, Wallace WA, Manning PA. Surgery within 6 months of an acute rotator cuff tear significantly improves outcome. J Shoulder Elbow Surg 2015;24:1876-1880.

8. Drummond MF, Sculpher MJ, Torrance GW, O'Brien BJ, Stoddart GL. Methods for the economic evaluation of health care programmes, 3rd edition. New York: Oxford University Press, 2005.

9. Kuye IO, Jain NB, Warner L, Herndon JH, Warner JJ. Economic evaluations in shoulder pathologies: A systematic review of the literature. J Shoulder Elbow Surg 2012;21:367-375.

10. Porter ME. What is value in health care? $N$ Engl J Med 2010;363:2477-2481.

11. Neumann PJ, Cohen JT, Weinstein MC. Updating costeffectiveness - The curious resilience of the \$50,000-perQALY threshold. N Engl J Med 2014;371:796-797.

12. Patte D. Classification of rotator cuff lesions. Clin Orthop Relat Res 1990;254:81-86.

13. Fuchs B, Weishaupt D, Zanetti M, Hodler J, Gerber C. Fatty degeneration of the muscles of the rotator cuff: Assessment by computed tomography versus magnetic resonance imaging. J Shoulder Elbow Surg 1999;8:599-605.

14. Imhoff AB, Fu FH, Ticker JB, Dunitz M. An atlas of shoulder arthroscopy. London: Informa Healthcare, 2003.

15. Herdman M, Gudex C, Lloyd A, et al. Development and preliminary testing of the new five-level version of EQ-5D (EQ-5D-5L). Qual Life Res 2011;20:1727-1736.

16. Ludwig K, Graf von der Schulenburg JM, Greiner W. German value set for the EQ-5D-5L. Pharmacoeconomics 2018;36:663-674.
17. Grobet C, Marks M, Tecklenburg L, Audigé L. Application and measurement properties of EQ-5D to measure quality of life in patients with upper extremity orthopaedic disorders: A systematic literature review. Arch Orthop Trauma Surg 2018;138:953-961.

18. Huber W, Hofstaetter JG, Hanslik-Schnabel B, Posch M, Wurnig C. The German version of the Oxford Shoulder Score-Cross-cultural adaptation and validation. Arch Orthop Trauma Surg 2004;124:531-536.

19. Gilbart MK, Gerber C. Comparison of the subjective shoulder value and the Constant score. J Shoulder Elbow Surg 2007; 16:717-721.

20. Constant CR, Gerber C, Emery RJ, Søjbjerg JO, Gohlke F, Boileau P. A review of the Constant score: Modifications and guidelines for its use. J Shoulder Elbow Surg 2008;17: 355-361.

21. Audigé L, Flury M, Müller AM, , ARCR CES Consensus Panel, Durchholz H. Complications associated with arthroscopic rotator cuff tear repair: Definition of a core event set by Delphi consensus process. J Shoulder Elbow Surg 2016;25:1907-1917.

22. Reilly MC, Zbrozek AS, Dukes EM. The validity and reproducibility of a work productivity and activity impairment instrument. Pharmacoeconomics 1993;4: 353-365.

23. Walters SJ, Brazier JE. Comparison of the minimally important difference for two health state utility measures: EQ-5D and SF-6D. Qual Life Res 2005;14:1523-1532.

24. Harris PA, Taylor R, Thielke R, Payne J, Gonzalez N, Conde JG. Research electronic data capture (REDCap) - A metadata-driven methodology and workflow process for providing translational research informatics support. J Biomed Inform 2009;42:377-381.

25. Briggs AH, Wonderling DE, Mooney CZ. Pulling costeffectiveness analysis up by its bootstraps: A non-parametric approach to confidence interval estimation. Health Econ 1997;6:327-340.

26. Reilly Associates Health Outcomes Research. Work Productivity and Activity Impairment - Specific Health Problem Questionnaire Version 2.0 (WPAI-SHP) Vol 2019. Margaret Reilly Associates, Inc., 2002. Available from: http://www. reillyassociates.net/Index.html.

27. Gerber C, Fuchs B, Hodler J. The results of repair of massive tears of the rotator cuff. J Bone Joint Surg Am 2000;82:505-515.

28. Hao Q, Devji T, Zeraatkar D, et al. Minimal important differences for improvement in shoulder condition patient-reported outcomes: A systematic review to inform a BMJ rapid recommendation. BMJ Open 2019;9:e028777.

29. van Kampen DA, Willems WJ, van Beers LW, Castelein RM, Scholtes VA, Terwee CB. Determination and comparison of the smallest detectable change (SDC) and the minimal important change (MIC) of fourshoulder patient-reported outcome measures (PROMs). J Orthop Surg Res 2013;8:40.

30. Mather RC 3rd, Koenig L, Acevedo D, et al. The societal and economic value of rotator cuff repair. J Bone Joint Surg Am 2013;95:1993-2000.

31. Makhni EC, Swart E, Steinhaus ME, et al. Cost-effectiveness of reverse total shoulder arthroplasty versus 
arthroscopic rotator cuff repair for symptomatic large and massive rotator cuff tears. Arthroscopy 2016;32:1771-1780.

32. Dornan GJ, Katthagen JC, Tahal DS, et al. Cost-effectiveness of arthroscopic rotator cuff repair versus reverse total shoulder arthroplasty for the treatment of massive rotator cuff tears in patients with pseudoparalysis and nonarthritic shoulders. Arthroscopy 2017;33: 716-725.

33. Murphy J, Gray A, Cooper C, Cooper D, Ramsay C, Carr A. Costs, quality of life and cost-effectiveness of arthroscopic and open repair for rotator cuff tears: An economic evaluation alongside the UKUFF trial. Bone Joint J 2016;98-B:1648-1655.

34. Adla DN, Rowsell M, Pandey R. Cost-effectiveness of open versus arthroscopic rotator cuff repair. J Shoulder Elbow Surg 2010;19:258-261.
35. Vitale MA, Vitale MG, Zivin JG, Braman JP, LU Bigliani, Flatow EL. Rotator cuff repair: An analysis of utility scores and cost-effectiveness. J Shoulder Elbow Surg 2007;16: $181-187$.

36. Carr AJ, Cooper CD, Campbell MK, et al. Clinical effectiveness and cost-effectiveness of open and arthroscopic rotator cuff repair [the UK Rotator Cuff Surgery (UKUFF) randomised trial]. Health Technol Assess 2015;19:1-218.

37. Eichler K, Krass A, Fendl A, Thüring N, Brügger U. [Integrated care for patients with heart failure in Switzerland: A cost analysis]. Praxis 2009;98:809-815. In German.

38. Moosmayer S, Lund G, Seljom US, et al. At a 10-year follow-up, tendon repair is superior to physiotherapy in the treatment of small and medium-sized rotator cuff tears. J Bone Joint Surg Am 2019;101:1050-1060. 